\title{
Effects of Poly (amino acid)s on Photophosphorylation in a Cyanobacterial Thylakoid
}

\author{
by Sachio Miyairi, Toshiaki Ichimura, Ikuo Matsui \\ and Koichi Honda
}

National Chemical Laboratory for Industry, 1-1 Higashi, Tsukuba-shi 305, Japan

Poly-L-glutamic acid accelerated by about $25 \%$ the cyclic photophosphorylation in the thylakoid of thermophilic cyanobacterium. A mixture of poly-L-glutamic acid and poly-L-ornithine of a ratio $2 / 1$ (w/w) also enhanced by $20 \sim 30 \%$ the photophosphorylation. The acceleration behaviors by poly- L glutamic acid alone are different from those by the mixture of acidic and basic poly (amino acid) s.

Key word : Cyanobacterium, Photophosphorylation, Poly (amino acid), Thermophile, Thylakoid membrane.

Basic poly (amino acid)s such as poly-L-lysine and poly-L-ornithine inhibited the cyclic photophosphorylation in the thylakoid of the thermophilic cyanobacterium, Synechococcus sp. by uncoupling the thylakoid membrane ${ }^{1)}$. It was also suggested that these poly (amino acid)s block the function of cytochrome c-553, a soluble electron carrier between photosystem 2 and photosystem $1^{11}$. The degree of these effects was related to molecular weights of the polymers ${ }^{1)}$. On the other hand, polyL-histidine did not affect the activities of the thylakoid "). These results suggest that the charge and structure of poly (amino acid)s have a significant effect on the thylakoid activities. Recently, we have studied on effects of poly-L-glutamic acid and a mixture of poly-L-glutamic acid and poly-L-ornithine on the thylakoid activities. Some of the results will be shown below.

The cells of the thermophilic cyanobacterium, Synechococcus sp., were cultivated at $50^{\circ} \mathrm{C}$ as reported previously ${ }^{2)}$. The spheroplasts were prepared from the cells by the lysozyme-osmotic shock treatment and used for thylakoid preparation $^{3)}$. Cyclic photophosphorylation mediated by phenazine methosulfate was measured for $1 \mathrm{~min}$

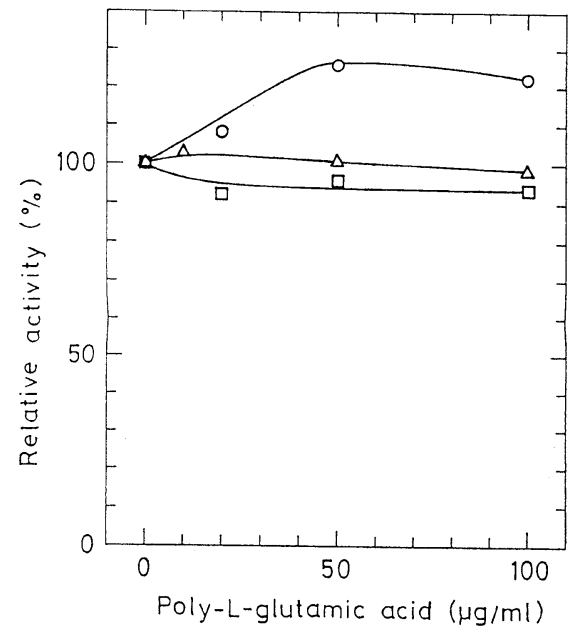

Fig. 1 Effects of poly-L-glutamic acid on the thylakoid activities.

$\bigcirc$ : photophosphorylation, $\square: \Delta \mathrm{pH}$, $\triangle$ : electron flow. Without added polyL-glutamic acid, the activity of the photophosphorylation and electron flow were $580 \mu \mathrm{mol} \mathrm{ATP} / \mathrm{mg} \mathrm{Chl} \mathrm{h}$ and 304 $\mu \mathrm{eq} / \mathrm{mg} \mathrm{Chl}$ h, respectively.

at $40^{\circ} \mathrm{C}$ and $\mathrm{pH} 7.0$ as previously reported ${ }^{3)}$. Formation of $\mathrm{H}^{+}$-gradient $(\Delta \mathrm{pH})$ across the thylakoid membrane coupled with light-induced cyclic electron flow was measured as fluorescence decrease 
Table 1 Effects of poly (amino acid)s on the thylakoid activities

\begin{tabular}{cccrc}
\hline \multicolumn{2}{c}{ Poly (amino acid) $(\mu \mathrm{g} / \mathrm{m} l)$} & \multicolumn{3}{c}{ Activity $(\%)$} \\
Poly-L-glutamic acid & Poly-L-ornithine & Photophosphorylation & $\Delta \mathrm{pH}$ & Electron flow \\
\hline 0 & 20 & 23 & 76 & 112 \\
40 & 20 & 123 & 119 & 107 \\
0 & 50 & 6 & 53 & 129 \\
100 & 50 & 130 & 128 & 101 \\
\hline
\end{tabular}

${ }^{*}$ Activities are expressed as percent of the activity in the absence of poly (amino acid).

of 9-aminoacridine for $10 \mathrm{sec}$ at $40^{\circ} \mathrm{C}$ and $\mathrm{pH}$ $7.5^{3.4)}$. Electron flow mediated by photosystem 1 was measured as oxygen uptake with a Clark-type electrode for $10 \mathrm{sec}$ at $40^{\circ} \mathrm{C}, \mathrm{pH} 7.5^{3)}$. In all the experiments, poly (amino acid) was added to the reaction mixture before the addition of spheroplasts. Poly-L-glutamic acid (Mw. 60,000) and poly-L-ornithine (Mw. 200,000) were obtained from Sigma.

Poly-L-glutamic acid accelerated by $26 \%$ at maximum the photophosphorylation in the thylakoids, but scarcely affected $\Delta \mathrm{pH}$ formation and electoron transport (Fig. 1). These results indicate that poly-L-glutamic acid does not affect ability of the thylakoid membranes to retain $\Delta \mathrm{pH}$ in contrast to other poly (amino acid)s such as poly-Lornithine and poly-L-lysine. There might be a possibility that poly-L-glutamic acid increases catalytic activity of coupling factors of the cyanobacterium. By the addition of Na-glutamate at concentrations of 50 and $100 \mu \mathrm{g} / \mathrm{ml}$, the photophosphorylation rates became 100 and $86 \%$ of the control value of activity, respectively. So, the effect of poly-L-glutamic acid might not be ascribed only to its ionic property. Even if poly-L-glutamic acid may have some ionic effect on the substrates (ATP and inorganic phosphorus), $50 \mu \mathrm{g} / \mathrm{ml}$ of the polymer is equivalent to only $0.35 \mathrm{mM}$ as glutamic acid residue, which is lower than the substrate concentration (1 $\mathrm{mM})$.

Poly-L-ornithine inhibited markedly the photophosphorylation (Table 1) by uncoupling the thylakoid membranes ${ }^{1)}$, while mixtures of polyL-glutamic acid and poly-L-ornithine of a ratio of $2 / 1$ (w/w) enhanced by $23 \sim 30 \%$ the photophosphorylation (Table 1). $\Delta \mathrm{pH}$ was also increased a little by the poly (amino acid)s mixtures, though the electron transport was nearly affected. These results suggest that the photophosphorylation was accelerated by the increase of $\Delta \mathrm{pH}$ which is a main driving force of the reaction. The reason of the $\Delta \mathrm{pH}$ increase is not yet clear. As a possibility, the acidic and basic poly (amino acid)s form polyionic complexes, which suppress leak of $\mathrm{H}^{+}$through the thylakoid membrane by stabilizing the membrane. It might be probable that the thylakoid membrane became unstable and partially uncoupled during the preparation process, and then polyionic complexes repaired the membrane stability.

In summary, though the degree of acceleration is not so large in any cases, poly-L-glutamic acid alone and the mixture of acidic and basic poly (amino acid) s accelerate the photophosphorylation probably in different ways .

\section{References}

1) Ichimura T., Miyairi S., Matsui I. and K. Honda : Membrane, 13, 117 (1988).

2) Yamaoka T., Satoh K. and S. Katoh : Plant\& Cell Physiol., 19, 943 (1978).

3) Miyairi S. : Membrane, 9, 37 (1984).

4) Pick U. and M. E. McCarty: Methods in Enzymology Vol. 69, ed. by Pietro A. S., Academic Press. New York pp. 538-546 (1980).

（受付 1989. . ) 